\title{
UM ESTUDO SOBRE AS POSSÍVEIS CAUSAS DE EVASÃO EM CURSO DE LICENCIATURA EM PEDAGOGIA A DISTÂNCIA
}

\author{
UN ESTUDIO SOBRE LA POSIBLE DESERCIÓN EN CURSO PROVOCA DE \\ BACHILLER EN EDUCACIÓN LA DISTANCIA
}

\section{A STUDY ON THE POSSIBLE ONGOING DROPOUT CAUSES OF BACHELOR IN EDUCATION THE DISTANCE}

\author{
Stelamary Aparecida Despincieri LAHAM ${ }^{1}$ \\ Sebastião de Souza LEMES ${ }^{2}$
}

RESUMO: Este estudo teve como objetivo geral de pesquisa investigar quais as possíveis causas que influenciaram a evasão de cursos a distância, pela percepção dos estudantes. Para isso, foi realizado um estudo exploratório descritivo de abordagem qualitativa com base em estudo de caso acerca dos índices e das causas da evasão no curso da UAB-UFSCAR Universidade Federal de São Carlos, no Polo de Apoio Presencial de Tarumã, um município do interior do Estado de São Paulo. Os participantes foram os estudantes desistentes, formados e ativos do curso de Licenciatura em Pedagogia UAB-UFSCar, das turmas de 2008, 2010, 2012 e 2013. Os instrumentos de coleta de dados utilizados foram: levantamento de revisão bibliográfica, documentos da Instituição para averiguar os reais índices de evasão, questionários respondidos pelos alunos das turmas em questão. O conteúdo das respostas dos estudantes ao questionário foi base para o levantamento e análise de categorias e subcategorias referentes a desistência na Educação a Distância. Essas categorias e subcategorias foram discutidas tendo em vista o referencial teórico, dando origem as causas exógenas e causas endógenas da evasão ao curso. Sendo assim, as causas exógenas são aquelas com relação a fatores externos à instituição e ao curso em questão, são elas: falta de tempo para o estudo, demanda profissional e familiar, problemas de saúde na família e pessoal. As causas endógenas são aquelas diretamente relacionadas à instituição de ensino ofertante do curso, como: falta de comunicação da tutoria, problemas com material didático, interação e interatividade no ambiente virtual de aprendizagem (sentimento de solidão), curso que não atende o perfil do aluno. Os resultados alcançados podem servir de subsídios às instituições de ensino superior que oferecem essa modalidade, principalmente como indicativo para a formulação de projetos pedagógicos de cursos a distância e que estejam preocupados em diminuir a incidência de evasão.

PALAVRAS-CHAVE: Educação a Distância. Evasão. Evasão na Educação a Distância. Causas de Evasão. Licenciatura em pedagogia a distância.

\footnotetext{
1 Mestre em Educação pelo o Programa de Mestrado em Educação Escolar da UNESP -Araraquara stelamary@gmail.com

2 Professor Doutor Docente do Programa de Mestrado em Educação Escolar da UNESP -Araraquara ss.lemes2@gmail.com
} 
RESUMEN: Este estudio tuvo como objetivo investigar qué investigar las posibles causas que influyeron en la evitación de cursos a distancia, la percepción de los estudiantes. Para esto, se realizó un estudio exploratorio descriptivo cualitativo basado en estudio de caso sobre las tarifas y la evitación de las causas en el curso de la Universidad Federal UAB-UFSCAR de San Carlos, en el apoyo de la cara del polo de Tarumã, en un municipio del interior Estado de Sao Paulo. Los participantes fueron abandonos, graduados y estudiantes de Grado activos en UAB-UFSCar Educación, las clases de 2008, 2010, 2012 y 2013. Los instrumentos de recolección de datos utilizados fueron: revisión de la literatura de elevación documentos de la Institución para determinar las tasas de abandono reales, los cuestionarios aplicados a los estudiantes de las clases en cuestión. El contenido de las respuestas de los estudiantes al cuestionario fue la base para el estudio y análisis de las categorías y subcategorías relacionadas con la retirada de la educación a distancia. Estas categorías y subcategorías se discutieron en vista del marco teórico, lo que lleva a las causas exógenas y endógenas causas de la evasión por supuesto. Por lo tanto, las causas exógenas son aquellos con respecto a los factores externos a la institución y el supuesto de que se trate, que son: la falta de tiempo para estudiar, exigencias laborales y familiares, problemas de salud de la familia y el personal. causas endógenas son los directamente relacionados con la oferta de la institución educativa curso, tales como: falta de tutoría de comunicación, problemas con los materiales de enseñanza, la interacción y la interactividad en el entorno virtual de aprendizaje (sensación de soledad), por supuesto que no cumple con el perfil del estudiante. Los resultados obtenidos pueden proporcionar apoyo a las instituciones de educación superior que ofrecen este tipo, sobre todo como un indicador para el desarrollo de proyectos pedagógicos de los cursos a distancia y se ocupan de la reducción de la incidencia de la evasión.

PALAVRAS-CLAVE: Educación a distancia. Escape. Evasión en la educación a distancia. Causas Evasión. Licenciado en Educación a Distancia

ABSTRACT: This study aimed to investigate which were the possible causes that influenced the distance learning courses dropouts from the students'perceptions. For this, it was carried out a descriptive exploratory study using a qualitative approach based on a case study about the evasion rates and causes in the course in the UABUFSCAR Federal University of São Carlos, in the Polo de Apoio Presencial of Tarumã - Support Face-to-Face Unit in Tarumã, a countryside town of the São Paulo State. The participants were the evaded students, graduated ones and attending students of the Pedagogy Licenciateship course UAB-UFSCar in the 2008, 2010, 2012 and 2013 classes. The used instruments for data collection were: a research of bibliographical review, the institution documents to ascertain the actual dropout rates, questionnaires answered by the students from mentioned classes. The contents of students' responses to the questionnaires were the basis for the survey and analysis of categories and subcategories related to Distance Education dropout. These categories and subcategories were discussed considering the theoretical framework, leading to exogenous and endogenous causes for the course evasion. Thus, the course exogenous causes were related to the external factors of the institution and the course, they are: lack of time to study, work and family demands, personal or familiar health problem. Endogenous causes were directly related to the educational institution, like: lack of tutoring communication, problems with teaching materials, interaction and interactivity 
in the virtual learning environment (feeling of loneliness), unsuited course design for the student's profile. The achieved results may provide support to higher education institutions which offer this modality as an indicator for the development of pedagogical projects of distance learning courses, and are concerned about the reduction of evasion incidence.

KEYWORDS:Distance Education. Evasion. Evasion in Distance Education. Causes Evasion. Pedagogy Licenciateship in Distance Education.

\section{Introdução}

O reconhecido avanço da Tecnologia da Informação e da Comunicação tem provocado mudanças visíveis no cotidiano das pessoas, que passaram a obter acesso cada vez maior à informação, bem como a outras formas de comunicação. Esse progresso também impulsionou mudanças na Educação e no Sistema Educativo, desde a necessidade de utilizar as tecnologias em prol de uma educação de qualidade, ao desafio de ir além da informação e promover a aquisição de conhecimento.

Dessa forma, com o desenvolvimento das novas tecnologias de informação e comunicação a - Educação a Distância $(\mathrm{EaD})$ ganhou uma diferente configuração a partir da utilização das ferramentas digitais. A Educação a Distância tem crescido no Brasil com grande velocidade e objetivando suprir a necessidade de levar formação superior e especialização a uma parcela da população que, por diversos fatores, não teria condições de frequentar um curso presencial. Assim, além do intuito de promover o acesso à formação acadêmica oportunizando a construção de conhecimentos, a educação a distância também tem por finalidade promover a inclusão social, promovendo o acesso ao ensino.

A educação é uma das principais bases para o crescimento econômico e social de um país. Devido à extensão territorial do Brasil, a expansão da Educação Superior no país é um desafio para os seus governantes. Dessa forma, a EaD vem ao encontro dessa necessidade, e tem o potencial de minimizar os problemas territoriais e democratizar a educação superior no país (PACHECO, 2011).

Segundo Litwin (2001), o desenvolvimento da modalidade de Educação a Distância nos últimos anos permitiu que fossem implementados projetos educacionais dos mais diversos em situações distintas e complexas. Para essa autora, esses programas ofertados são caracterizados pela flexibilidade inerentes às múltiplas possibilidades oferecidas pela $\mathrm{EaD}$. 
O Ministério da Educação (MEC) divulgou no Censo de 2009, que houve, no nível de graduação em $\mathrm{EaD}$, um crescimento estimado superior a 90\% comparado ao número de alunos em 2008. Isso tem demonstrado a evolução significativa da $\mathrm{EaD}$ no Brasil. De acordo com o Inep ${ }^{3}$ - Instituto Nacional de Estudos e Pesquisas Educacionais Anísio Teixeira: "Entre 2011 e 2012, as matrículas avançaram 12,2\% nos cursos a distância e 3,1\% nos presenciais. Com esse crescimento, a modalidade a distância já representa mais de $15 \%$ do total de matrículas em graduação".

Autores como Gonçalves (2006); Rezer (2009) e Santos (2011) apontam que uma das causas de expansão acentuada da EAD deve-se à criação, em 2006, da UAB Universidade Aberta do Brasil, a qual foi instituída pelo Decreto Federal No 5.800/2006 (BRASIL, 2006), visando "o desenvolvimento da modalidade de educação a distância, com a finalidade de expandir e interiorizar a oferta de cursos e programas de educação superior no País". Ela incentiva a colaboração entre a União e os entes federativos e estimula a criação de centros de formação permanentes por meio dos polos de apoio presencial em localidades estratégicas.

Um dos eixos fundamentais do sistema UAB é a expansão pública da educação superior, considerando os processos de democratização e acesso. Porém, sua prioridade são os professores que atuam na Educação Básica sem formação superior. (BRASIL, 2006). Dessa forma, a UAB apresenta-se como uma ferramenta educacional de formação em disciplinas com escassez de professores para os anos finais do Ensino Fundamental e Médio.

Nesse sentido, não basta apenas o acesso, mas a permanência e a conclusão dos cursos. De acordo com o "Censo EaD.BR - Relatório Analítico da Aprendizagem a Distância no Brasil 2012”, realizado pela Associação Brasileira de Educação a Distância (ABED), o maior índice de evasão é apresentado pelas Instituições públicas atingindo $21,1 \%$ dos alunos matriculados, seguido e nas Instituições privadas, cujo índice chega a $18,5 \%$.

Esses dados evidenciam que mesmo com o crescimento da oferta de cursos nessa modalidade, a evasão se apresenta como um problema em relação à democratização e acesso à educação superior. De acordo com Santos et al (2008, p.3) a evasão diz respeito à desistência definitiva do estudante em qualquer etapa do curso.

${ }^{3}$ INEP - Instituto Nacional de Estudos e Pesquisas Educacionais Anísio Teixeira. Brasil teve mais de 7 milhões de matrículas no ano passado. Brasília, 17 set. 2013. Disponível em: <http://portal.inep.gov.br/visualizar//asset_publisher/6AhJ/content/ brasil-teve-mais-de-7-milhoes-de-matriculas-no-ano-passado>. Acesso em: 20 jan. 2015 . 
Mas os índices de desistência na modalidade EaD são altos, não somente no Brasil, conforme Obbadi e Jurberg (2005, p.49) cujos estudos apontam que na Europa a porcentagem de desistência oscila entre 20 e 30\% e nos Estados Unidos e países asiáticos esse percentual é da ordem de $50 \%$ dos matriculados.

Ao observar os dados da ABED (2013), também extraídos do Censo EaD.BR, vemos que $36 \%$ das instituições participantes do estudo apontaram a evasão como o principal problema enfrentado na oferta de educação a distância. Numa escala que varia de um a sete para medir o grau de utilização de ferramentas e métodos de avaliação dos recursos e serviços presentes nos cursos de $\mathrm{EaD}$, a realização do controle de evasão de estudantes obteve nota média 5,58.

Nesse sentido, a busca das causas de evasão apontadas pelos estudantes de cursos oferecidos nessa modalidade pode fornecer subsídios importantes para as instituições de ensino, que passariam a fazer um trabalho preventivo para reduzir os níveis de evasão.

Moura-Walter (2006) ressalta que a evasão tem gerado muitas pesquisas no Brasil e é caracterizada como um problema recorrente, mas com foco no ensino fundamental e médio e na modalidade presencial, apresentando poucos estudos relacionados à modalidade a distância. Confirmando essa afirmação, Abbad e BorgesAndrade (2006) ressaltam que existem na literatura poucos estudos sistemáticos sobre evasão na área de $\mathrm{EaD}$, apesar deste ser um dos principais problemas da área.

De acordo com Vilarinho e Paro (2008) os motivos que levam à evasão são: motivos administrativos; pedagógicos; pessoais e tecnológicos. Além disso, a evasão pode também ser influenciada por necessidades individuais e regionais e pela avaliação do curso por parte dos alunos, tendo relação com a credibilidade das instituições ofertantes.

Santos et al (2008), ao pesquisarem os motivos junto a alunos evadidos de um curso de Ciências Biológicas a Distância, encontraram outros problemas: (a) procura da graduação a distância em determinada área por falta de opções em outras áreas; (b) trabalho em tempo integral (40 horas), gerando pouco tempo para os estudos, baixo desempenho acadêmico e dificuldades de aprendizagem.

Partindo dessas constatações, considera-se o presente estudo relevante visto que fornecerá dados que poderão subsidiar projetos pedagógicos voltados à $\mathrm{EaD}$ que venham a corresponder às necessidades desses estudantes. 
Dessa maneira, buscou-se com o presente estudo investigar as possíveis causas da evasão em EaD, dando voz aos alunos evadidos, formados e ativos no referido curso, com o intuito de responder os seguintes questionamentos: $\mathrm{O}$ que os estudantes evadidos indicam como impedimento para concluir o curso? Quais as principais dificuldades apontadas por esses estudantes? Quais os fatores que influenciam o abandono do curso?

Nessa perspectiva, para responder a esses questionamentos foi definido como objetivo geral dessa pesquisa: Identificar e analisar as possíveis causas da evasão nas primeiras turmas do curso de Pedagogia UAB - UFSCar.

Uma vez traçado o objetivo geral, considera-se necessário traçar os seguintes Objetivos Específicos: (a) Identificar os índices de evasão nas duas primeiras turmas dos cursos de graduação em Licenciatura em Pedagogia; (b) Identificar as causas de evasão, percebidas pelos alunos evadidos, nas quatro primeiras turmas dos cursos de graduação em Licenciatura em Pedagogia e (c) Analisar os motivos de desistência relatados pelos alunos do referido curso.

Com a finalidade de contribuir para minimizar esses índices de evasão e buscar responder às indagações postas neste estudo, optou-se pela Abordagem Qualitativa, pesquisa empírica de cunho exploratório.

\section{Evasão na Educação a Distância no Brasil}

O Censo EAD.BR - Relatório Analítico da Aprendizagem a Distância no Brasil, informa que em 2013, o maior obstáculo apontado pelas instituições que oferecem cursos na modalidade a distância no Brasil é a evasão. Das Instituições participantes do Censo, $15,4 \%$ indicaram a evasão como maior problema enfrentado na execução dos cursos.

Segundo a referida pesquisa, o índice varia de acordo com o tipo de $\mathrm{EaD}$ praticado, uma vez que para disciplinas ministradas a distância em cursos presenciais a evasão é menor, com percentual de 10,49\%, sendo que entre os alunos dos cursos regulamentados oferecidos totalmente a distância o índice de evasão é de 16,94\%.

Outro documento importante é o Anuário Brasileiro Estatístico de Educação Aberta e a Distância (ABRAEAD), de 2008, em sua edição mais recente, que classifica as instituições em dois grupos: o primeiro refere-se as que têm evasão menor ou igual a $30 \%$ e o outro com evasão superior a $30 \%$. Essa investigação verificou que o percentual 
de instituições com uma evasão alta (superior a 30\% dos alunos) é de $11 \%$ das que responderam à questão. 75\% apontaram uma evasão igual ou inferior a $20 \%$.

\section{A pesquisa}

A evasão na $\mathrm{EaD}$ é objeto em torno do qual se constituiu o problema de pesquisa. A partir da análise do que vem sendo produzido em relação ao fenômeno da evasão nessa modalidade de ensino, buscou-se elaborar questões que favorecessem a construção de novos conhecimentos sobre esse campo de pesquisa na atualidade.

André e Lüdke (1986, p. 2) destacam a importância do papel da pesquisa para os educadores, uma vez que ela deve fazer parte das atividades normais dos professores, administradores e supervisores. Também ressaltam,

O pesquisador, como membro de um determinado tempo e de uma específica sociedade, irá refletir em seu trabalho de pesquisa os valores, os princípios considerados importantes naquela sociedade, naquela época.

Em consonância com que afirmam André e Ludke é possível compreender que para alcançar o propósito dessa pesquisa se faz necessário delinear os caminhos da pesquisa descrevendo os procedimentos metodológicos selecionados, o tipo de pesquisa, o seu contexto de investigação, o instrumento utilizado, além dos procedimentos de coleta e a análise dos dados.

A coleta de dados para esta pesquisa for organizada em três etapas. Num primeiro momento foi realizada uma revisão bibliográfica com o intuito de compreender a educação a distância no contexto atual brasileiro e de averiguar o que mostram as pesquisas recentes sobre a evasão em cursos na modalidade a distância. Desse modo, a partir da análise das bases conceituais da $\mathrm{EaD}$ e da legislação vigente, assim como a revisão teórica sobre a temática, foram feitos apontamentos de livros, periódicos, artigos científicos e teses e dissertações buscando selecionar informações relevantes e consistentes para essa pesquisa.

A segunda etapa foram levantados os índices de evasão dos alunos das quatro turmas do curso de Pedagogia UAB-UFSCar, do Polo UAB do município de Tarumã - SP, por meio de documentação oficial da instituição. 
A terceira etapa teve por finalidade identificar as causas apontadas pelos estudantes das turmas de 2008, 2010, 2012 e 2013, do curso em questão. Para isso, foram feitas perguntas abertas e fechadas, por meio da ferramenta Google Doc's e as informações colhidas nos questionários deram base para a construção das categorias para posterior análise.

Segundo Stake (2011), a análise dos dados implica na organização de todo material buscando relações e inferências. Desse modo, após os dados coletados, as informações foram tratadas por meio da técnica de análise de conteúdo, segundo pressupostos metodológicos propostos por Bardin (2008), com base na técnica de análise categorial temática.

A referida técnica se constitui numa metodologia usada para descrever e interpretar o conteúdo de toda classe de documentos e textos, conduzindo a descrições sistemáticas qualitativas ou mesmo quantitativas que ajudam a reinterpretar as mensagens e a atingir uma compreensão de seus significados. Cabe ressaltar que como método de investigação essa análise compreende procedimentos especiais para o processamento de dados científicos.

Por fim, cabe destacar que todas as categorias de resposta foram discutidas e interpretadas à luz do referencial teórico que norteou essa pesquisa.

\section{Resultados e Discussões}

A análise de conteúdo das manifestações obtidas nos dois questionários respondidos aplicados aos estudantes, sejam eles evadidos, ativos ou formados das quatro turmas do curso a distância de Licenciatura em Pedagogia UAB-UFSCar, do Polo UAB de Tarumã, foi realizada com base na técnica de análise categorial proposta por Bardin (2008), portanto as categorias construídas com base nos discursos dos participantes traduzem o conteúdo básico existente no texto original.

Com base em critérios de semelhança de conteúdos, lógica e pertinência, procedeu-se a interpretação das verbalizações dos respondentes. Posteriormente, verificou-se que a categoria desistência está presente em ambos os questionários e a categoria persistência ligada às verbalizações do Questionário 02 - estudantes ativos e formados. Ainda, em relação ao instrumento de coleta de dados, considera-se relevante destacar que os questionários continham duas indagações comuns relacionadas à 
escolha da modalidade de educação a distância e à escolha do curso de Licenciatura em Pedagogia.

A partir da exploração do material foram determinadas duas categorias mais abrangentes, como já mencionadas anteriormente à primeira categoria desistência se subdivide em cinco subcategorias, em conformidade com as respostas aos dois questionários (Q1 e Q2), à categoria persistência observada apenas no Q2 são indicadas somente quatro subcategorias. Assim considera-se relevante destacar as cinco subcategorias que emergiram do Questionário 1 - Alunos Evadidos:

Quadro 06: Categorias de Motivos de Evasão - Estudantes Evadidos Q1 - Categoria Desistência - Questionário 01 Estudantes Evadidos

\begin{tabular}{|c|c|c|}
\hline Sub Categorias & Frequência & $\%$ \\
\hline 1. Falta de Tempo para o Estudo & 12 & $66 \%$ \\
\hline 2. Dificuldade em compreender o material didático & 11 & $61 \%$ \\
\hline 3. Sentimento de solidão & 11 & $61 \%$ \\
\hline 4. Curso fora do perfil do aluno ingressante & 09 & $50 \%$ \\
\hline 5. Falta de comunicação e orientação da tutoria & 08 & $44 \%$ \\
\hline
\end{tabular}

Fonte: Elaborado pela autora a partir das respostas do Questionário 1.

É possível observar no Quadro 06 que dentre os estudantes evadidos a maioria apresentou o fator tempo como o motivo mais forte para a desistência do curso.

A partir das subcategorias que surgiram por meio das respostas advindas do Questionário 02, enviados aos estudantes formados e ativos, foi elaborado o Quadro 7.

Quadro 7: Categorias de Motivos de Evasão - Estudantes Ativos e Formados Q2 - Categoria Desistência - Questionário 02 Alunos Ativos e Formados

\begin{tabular}{|l|c|c|}
\hline Sub Categorias & Frequência & $\mathbf{\%}$ \\
\hline 1. Falta de comunicação e orientação da tutoria & 20 & $40 \%$ \\
\hline 2. Dificuldade em compreender o material didático & 15 & $30 \%$ \\
\hline 3. Falta de Tempo para o Estudo & 12 & $24 \%$ \\
\hline 4. Polo distante da residência & 11 & $22 \%$ \\
\hline 5. Problemas de saúde pessoal ou familiar & 09 & $18 \%$ \\
\hline
\end{tabular}

Fonte: Elaborado pela autora a partir das respostas do Questionário 2.

$\mathrm{Na}$ busca de possíveis relações entre fatores que figuram entre as causas mais comumente associadas à evasão e à persistência dos alunos do curso de Licenciatura em Pedagogia, foi elaborado o Quadro 08: 
Quadro 8: Categorias de Motivos de Persistência - alunos ativos e formados. Q2 - Categoria Persistência - Questionário 2 Alunos Ativos e Formados

1. Empenho Pessoal Sub Categorias

2. Qualidade do Curso Frequência

3. Flexibilidade de Horário para estudo

4. Instituição Conceituada

Fonte: Elaborado pela autora a partir das respostas do Questionário 2.

\section{Análise das Categorias}

A partir da análise das respostas dos estudantes, emergiram quatro fatores relacionados à escolha da modalidade e do curso: tempo, autonomia para os estudos, gratuidade do curso e facilidade. O fator tempo aparece em 57,3\% das respostas, já autonomia para os estudos $33 \%$ delas, as duas últimas categorias: gratuidade e facilidade representam $7,35 \%$ das respostas.

No tocante ao fator "tempo", autores como Belloni (2002) e Rezer (2011) destacam que existem equívocos por parte dos estudantes em relação àideia de tempo, uma vez que:

Um dos argumentos mais frequentemente utilizados em favor da disseminação da EAD diz respeito à escalabilidade, isto é, à possibilidade de otimização de recursos, de modo a permitir que maior número de pessoas tenha acesso a cursos que, desenvolvidos presencialmente, estariam limitados à capacidade física de uma sala de aula ou de atendimento por um professor. No entanto, na mesma linha de raciocínio, não é incomum a percepção por parte dos alunos de que, uma vez suprimido o tempo de deslocamento para assistir aulas presenciais, é possível, na EAD, participar de mais de um curso ou cursar mais disciplinas, concomitantemente, do que faria na modalidade de ensino presencial. Essa percepção equivocada da necessidade de tempo para os estudos tem gerado tensões que ultrapassam a dimensão do tempo do relógio e os aspetos exclusivamente pragmáticos dessa modalidade educacional. (REZER, 2011, p.40)

De acordo com o que diz Rezer (2011) em relação à ideia de tempo, evidencia-se nas falas dos estudantes um equívoco em relação ao conceito de tempo necessário para os estudos.

Em relação ao termo autonomia para os estudos, Borges e Fagundes (2009) afirmam que a experiência de estudar a distância, pode proporcionar aos alunos maior autonomia porque existe a possibilidade de criarem uma nova forma de organizar o tempo, local e mecanismos de estudo. Isso pode ocorrer,devido às características 
inerentes à modalidade, devido ao fato das aulas não serem presenciais: uma vez que os estudantes podem realizar suas atividades em qualquer local e horário, tornando dispensável justificar faltas, em caso de problemas de família ou compromisso de trabalho.

Dentre as manifestações dos respondentes pode-se observar que os estudantes expressaram acreditar que a educação a distância lhes ofereceriam melhores condições para estudar e realizar suas tarefas sem sair de casas, sem a necessidade de deslocamento de cidades, de abdicação da família e do trabalho, o que para este eles era necessário e significativo.

Um fator que não se pode perder de vista é que dentre as 68 pessoas que responderam aos questionários, 59 delas são de estudantes do gênero feminino, ou seja, 86\%. Nessas manifestações, encontramos depoimentos afirmando que estudar a distância lhes proporcionaria condições de se organizar os estudos e cuidar da família e do trabalho de forma concomitante.

Belloni (2010) afirma que a EaD surge como oportunidade para as pessoas com dificuldade de tempo e de acesso ao ensino presencial para que possam realizar a graduação. Característica essa que oportuniza as pessoas moradoras em cidades distantes das Universidades a continuar com os estudos e concluir a graduação ou especialização.

Diante das manifestações dos estudantes e a frequência de respostas que apontam os fatores Tempo e Autonomia para os estudos, ficou evidenciado que os principais fatores a influenciar na escolha do curso e da modalidade, são permeados pela a racionalidade e o pragmatismo. Essas características demonstram a intenção de concluir efetivamente o curso escolhido, porém, os alunos podem mudar de percurso em virtude de suas experiências no decorrer do curso.

Ainda com relação ao tempo, na categoria Desistência, tanto no Questionário 1, quanto no Questionário 2, a subcategoria Falta de Tempo para os Estudos, emergiu das manifestações dos respondentes. Isso demonstrou que o principal motivo para a escolha da modalidade a distância seria ter mais tempo para os estudos. Porém durante a análise o das respostas apresentadas nos questionários aplicados foi possível perceber que esse motivo não se concretizou.

Em síntese, a análise dessas questões revelou a existência de uma compreensão equivocada em relação ao tempo na modalidade a distância. As discussões na área relacionadas ao tempo e ao espaço de aprendizagem que podem variar nessa 
modalidade, não estão relacionadas à duração e dedicação aos estudos, mas sim à possibilidade de organização desse tempo, tendo em a possibilidade dos estudantes poderem escolher aonde e quando estudar na modalidade e distância.

A interpretação inferencial teve como objetivo aprofundar a análise para além dos conteúdos manifestos, na tentativa de viabilizar e colocar em evidência as conexões com as bases teóricas e o contexto empírico aqui investigado. Assim, a pesquisa aqui descrita deixa evidente como um dos fatores de evasão se refere ao perfil sócio demográfico do estudante estando relacionado à composição familiar e ao estado civil dos alunos evadidos. Esse fator foi denominado na pesquisa como subcategoria Curso fora do perfil dos alunos ingressantes, sendo apresentado como fator de frequência verificado nas manifestações do Questionário 1- Estudantes Evadidos.

Palloff e Pratt (2004) destacam que a EaD proporciona aos estudantes a oportunidade de estudar em qualquer lugar e em qualquer tempo, o que permite que eles continuem trabalhando em turno integral e que deem atenção às suas famílias. Entretanto, pesquisas têm demonstrado que conciliar estudo, trabalho e família, ainda é uma das grandes dificuldades encontradas pelos alunos (Vargas, 2004; Moura - Walter, 2006; Oliveira, 2007).

A maioria dos participantes desta pesquisa declarou manter uma relação matrimonial, (64,70\%), e 85,29\% afirmaram que possuem entre 1 e 3 filhos, e que executavam atividades profissionais paralelas os estudos. Dessa forma, é possível concluir que o grupo pesquisado é composto por um conjunto de pessoas que responsáveis por inúmeros compromissos e, consequentemente, essas demandas simultâneas poderiam dificultar para o aluno planejar e seguir uma organização de estudo.

Nas manifestações dos participantes da pesquisa, foi possível perceber uma preocupação para suprir as necessidades econômicas pessoais e da família, demostrando que esses alunos submetiam-se a uma longa jornada de trabalho.

Segundo Umekawa \& Zerbini (2015), pesquisas sobre o fenômeno da evasão na $\mathrm{EaD}$, demonstram que as características sóciodemográficas do alunado são importantes para o entendimento da presença destes indivíduos nos cursos. Essas variáveis vêm sendo amplamente discutidas sendo compreendidas como facilitadores ou dificultadores à permanência dos alunos nos cursos dessa modalidade. Assim, é importante para as Instituições de Ensino Superior que oferecem cursos na modalidade $\mathrm{EaD}$, que realizem pesquisas sobre o perfil dos alunos ingressantes nos cursos, para que as ações 
instrucionais sejam planejadas e implementadas com base nas características da clientela (Abbad, 2005).

Outra subcategoria que emergiu das manifestações dos alunos participantes do Questionário 1, foi a dificuldade em compreender o material didático, o qual foi apontado como motivo relevante para abandono do curso, conforme descrito nos Quadro 6 e ou seja, tanto para os alunos evadidos, quanto para os ativos o material didático foi um complicador para a conclusão do curso ou um dificultador durante o curso.

De acordo com o Guia do Estudante (UAB-UFSCar, 2012) os materiais didáticos disponibilizados pelo curso de Licenciatura em Pedagogia UAB-UFSCar, são compostos por material impresso e as ferramentas do ambiente virtual de aprendizagem, os quais constituem os principais meios de comunicação e interação utilizadas no processo pedagógico.

Ainda de acordo com este Guia os materiais audiovisuais digitais do referido curso, são elaborados para apoiar as atividades pedagógicas e dividem-se em: videoaulas - que apresentam os conteúdos dos principais temas a serem abordados nas disciplinas do curso - e uma coletânea de vídeos, trazendo a proposta de formação do curso e suas disciplinas.

De acordo com o que propõem os Referenciais de Qualidade para a Educação Superior a Distância no que tange à importância de oferecer aos alunos um guia geral do curso e do conteúdo relativo a cada material, o curso de Pedagogia UAB-UFSCar atende aos requisitos de qualidade, o qual determina que "relativo ao conteúdo de cada material educacional, é importante que seja colocado à disposição dos estudantes um Guia - impresso e/ou digital (BRASIL, 2007, p.14)”.

Apesar de demonstrar uma preocupação da UAB-UFSCar em utilizar diversas mídias para contemplar os diferentes estilos de aprendizagem dos alunos, ao serem analisados as manifestações dos participantes dessa pesquisa, ficou evidente a dificuldade em compreender o material didático disponível. De acordo com Petri (2005, pg.20) o material didático para $\mathrm{EaD}$, “[...] necessita propiciar não somente ensino, mas, sobretudo, interação do autor com o estudante, por meio do texto.”, o que implica em dizer que um texto didático escrito para essa modalidade deve além de comunicar, fazer a socialização dos conhecimentos de forma interativa e dialética, tendo em vista que na $\mathrm{EaD}$, os interlocutores estão em tempos e espaços diferenciados. Nessa perspectiva, os 
participantes da pesquisa, evidenciaram problemas em interagir com os materiais didáticos e apontaram este como um fator motivador do abandono do curso.

Para Moore e Kearsley (2008), os textos didáticos para os cursos de EaD, necessitam ter algumas características importantes como a utilização de voz ativa, de pronomes pessoais, verbos de ação, de sentenças curtas, informações sucintas, palavras de fácil interpretação, sentenças e parágrafos em ordem lógica, cabeçalhos informativos, sumário, ilustrações, tabelas e gráficos para suplementar o texto. Segundo esses autores, as características citadas podem garantir aos estudantes uma maior familiaridade com o material, pois, o que realmente importa é o que o aluno irá fazer diante do texto, pois a aprendizagem somente ocorrerá por ação desse agente.

A subcategoria "Sentimento de Solidão" foi evidenciada pelo Questionário 1, como o quarto fator de maior relevância na decisão de abandonar o curso. A análise destasubcategoria apontou que os alunos se sentiam desestimulados a se manterem no curso porque não se consideravam integrantes de uma turma, sentindo-se isolados.

Além dos fatores já apresentados os participantes da pesquisa relataram problemas de comunicação com o tutor e falta de feedback sobre as atividades enviadas, também foram apontadas dificuldades em compreender o conteúdo sem a interação de tutores e colegas. Nas manifestações analisadas, averiguou-se que, apesar do uso de ferramentas interativas na plataforma de aprendizagem do curso e dos encontros presenciais nos polos, o sentimento de solidão existe. De acordo com Palloff\&Pratt (2004), esse sentimento de solidão se dá por problemas na qualidade da interação, pois, a interatividade na $\mathrm{EaD}$ é muito importante para evitar que os alunos desistam permanentemente do curso. A interação entre os próprios colegas do curso e entre os tutores coopera para a formação de uma comunidade virtual de aprendizagem, fazendo com que os alunos não se sintam sozinhos e aumente a oportunidade de sucesso nos estudos, diminuindo o abandono. Quanto à construção de uma comunidade de aprendizagem, as autoras ressaltam que:

Quanto maior a atenção que se dá ao desenvolvimento de um sentido de comunidade, mais os alunos tende a continuar no curso até o final. Se os alunos acreditarem que "estão nessa juntos", a possibilidade de retenção aumentará. (PALLOFF; PRATT, 2004, p. 141).

Nesse contexto, Moura (2014), afirma que além da formação de uma comunidade virtual de aprendizagem, existem algumas ações comportamentais que podem ser adotadas pela equipe de professores e tutores, com intuito de minimizar ou 
extinguir o sentimento de solidão nos cursos nessa modalidade. Essas ações, de acordo com o autor, dizem respeito a diretrizes de condução e à avaliação das atividades avaliativas do curso, nas quais se deve estabelecer um padrão de tempo de até 24 horas para que o tutor dê as respostas e feedbacks aos alunos.

Sendo assim, a presença constante dos alunos nos fóruns de discussão e nas demais ferramentas de interação assíncronas disponíveis na plataforma de aprendizagem, se daria pela agilidade com que os tutores lhe fornecessem os feedbacks, de forma a favorecer um acompanhamento mais individual e efetivo das atividades postadas na plataforma e minimizando o sentimento de solidão dos alunos.

Em continuidade às análises, é possível perceber mais um motivo apontado pelos alunos como sendo relevante para o abandono do curso, a Falta de comunicação e orientação da tutoria. Esta subcategoria é apontada nos dois questionários aplicados, ou seja, tanto no Questionário 1 - Alunos Evadidos e Questionário 2 - Alunos Ativos e Formados.

Para ampliar discussão a respeito dessa subcategoria é imprescindível conhecer qual o modelo de tutoria adotado pela UAB-UFSCar. Na referida instituição, o sistema de tutoria responsável é por gerenciar o trabalho dos tutores sendo que seu papel no processo ensino-aprendizagem na educação a distância prevê dois grupos de tutores: os virtuais e presenciais. Sendo assim, compreende-se como:

\begin{abstract}
a)Tutoria Presencial, composta por tutores que auxiliam e acompanham os estudantes em tempo síncrono e, presencialmente, por meio de encontros frequentes ou esporádicos; b) Tutoria Virtual, composta por tutores virtuais que acompanham e auxiliam os estudantes a distância (virtualmente), por meio de tecnologias de informação e comunicação." (ROSSET; ALVES, 2007).
\end{abstract}

De acordo com Rossetti (2007), na UAB-UFSCar, a atuação do tutor virtual esse dá na interação constante e frequente com os estudantes por meio de um ambiente virtual de aprendizagem, o qual possui várias ferramentas para interação, como fóruns e correio eletrônico interno. Seria função do tutor virtual acompanhar a execução de todas as tarefas realizadas pelos estudantes no Ambiente Virtual de Aprendizagem, atuando na solução de suas dúvidas sobre o conteúdo das disciplinas e orientando seus estudos. Já o tutor presencial tem a função de atuar na orientação síncrona dos alunos, sendo que atua na proporção de um tutor presenciais para cada vinte e cinco alunos e suas atividades dos envolvem solução de dúvidas dos alunos quanto à utilização do Ambiente Virtual de Aprendizagem e demais recursos tecnológicos, auxiliando-os na 
organização da agenda pessoal de estudos e apoiando-os nos momentos de realização das atividades e avaliações presenciais. Esses tutores atuam nos polos de apoio presencial, localizados nos municípios parceiros da UAB.

Portanto, de acordo com as funções atribuídas aos tutores virtuais e a distância, a importância que estes profissionais assumem no processo de ensino na $\mathrm{EaD}$, é imprescindível, posto que dentre suas atribuições constam o acompanhamento e orientação dos alunos no decorrer das disciplinas do curso.

Diante do contexto apresentado, essa pesquisa evidenciou que os alunos que apontaram problemas de comunicação e orientação da tutoria, não tiveram um acompanhamento acadêmico satisfatório. Eles relataram problemas de comunicação com o tutor, falta de feedback do tutor sobre as atividades enviadas, entre outros. Em síntese, essa subcategoria enfatiza problemas com relação à falta de interação entre os tutores e os alunos.

Os estudantes entrevistados consideraram, ainda, que os contatos da tutoria foram insuficientes, e que tiveram dificuldades para se comunicar com seus tutores. Além disso, apontaram que faltou apoio acadêmico, pouca orientação para realização de algumas tarefas.

Outros relatos evidenciaram que os participantes se sentiram descontentes com a atuação da tutoria, pois para muitos, foi o primeiro contato com essa modalidade o que dificultou ainda mais sem essa orientação inicial.

Esses resultados reforçam aqueles relatados por Oliveira (2007) em sua pesquisa sobre evasão, na qual a autora deixou evidente que os alunos haviam desistido de um curso por não terem recebido nenhum auxílio acadêmico. E outra pesquisa, MouraWalter (2006) aponta que a falta de apoio da tutoria foi o principal fator que levou os alunos a desistirem de um curso a distância.

O papel do tutor nos cursos a distância é imprescindível, o que é enfatizado por Souza et. al (2004), o qual destaca que o tutor é aquele que garante a inter-relação pessoal do aluno com o sistema no qual está inserido, viabilizando o alcance dos objetivos propostos pelo curso. Ele considera que é indispensável que o tutor desenvolva capacidades, competências e habilidades de acordo com sua função, para poder efetivar uma prática educativa política, mediatizadora e formativa. Assim, de acordo com os Referenciais de Qualidade para Educação Superior à Distância, o tutor é uma peça fundamental no desenvolvimento de cursos dessa modalidade: 
O corpo de tutores desempenha papel de fundamental importância no processo educacional de cursos superiores à distância e compõem quadro diferenciado, no interior das instituições. O tutor deve ser compreendido como um dos sujeitos que participa ativamente da prática pedagógica. Suas atividades desenvolvidas a distância e/ou presencialmente devem contribuir para o desenvolvimento dos processos de ensino e de aprendizagem e para o acompanhamento e avaliação do projeto pedagógico. REFERENCIAIS DE QUALIDADE PARA EDUCAÇÃO SUPERIOR A DISTÂNCIA. 2007, p. 21.

Dessa forma, a aprendizagem na $\mathrm{EaD}$ exige que o professor desempenhe um papel de facilitador, observador e monitor, para auxiliar o aluno no processo de interação. Além disso deve prestar, em tempo hábil, as informações necessárias oferecendo feedbacks de acordo com as necessidades dos alunos. Segundo ROSSETTI (2007, p. 12), o feedbacké a principal forma de se manter o aluno motivado, envolvido e conectado ao curso e, também, de conduzi-lo aos questionamentos e às reflexões mais profundas acerca dos tópicos abordados pelas disciplinas. "É por meio do feedback que o estudante saberá se está em um caminho apropriado para o aprendizado. Podemos dizer que o feedback é um processo contínuo, e não um fim.”(ROSSETTI; 2007).

Os alunos que responderam ao Questionário 2 - Alunos Ativos e Formados, em suas manifestações, deixaram evidente a subcategoria Polo distante da residência, na qual relataram que a distância entre o Polo de suas residências poderia ser um motivo de desistência do curso. Porém essa subcategoria não foi identificada nas manifestações dos alunos evadidos. Dessa forma, ao retomar os dados obtidos no levantamento do perfil dos participantes da pesquisa, foi possível verificar, por meio das afirmações abaixo, que a grande maioria reside próximo ao polo em que estavam matriculados e na cidade que abriga o Polo. Isso vem ao encontro da informação apresentada no Gráfico 5 - Distância da Residência ao Polo Presencial - em que apenas 13\% dos entrevistados residiam na cidade em que o Polo está instalado e $78 \%$ residiam a 10 a $25 \mathrm{~km}$ de distância.

Entretanto, os dados revelaram que, como os alunos não residem longe do polo de Apoio presencial, esse fator não parece ser relevante nas taxas de evasão das turmas analisadas, porém, podem vir a ser uma causa de desistência.Os alunos do curso de Pedagogia UAB-UFSCar, necessitam frequentar o Polo de apoio presencial em que estão matriculados para realização das atividades presenciais. Segundo depoimento dos alunos colhidos nos questionários, esses encontros presenciais são basicamente realizados para a execução das avaliações presenciais obrigatórias e podem acontecer de 
duas a três vezes no mês, de acordo com os alunos é importante que o polo seja próximo a residência.

A subcategoria Problemas de saúde pessoal ou familiar evidenciou que a motivação dos alunos em continuarem fazendo o curso poderia mudar em função de acontecimentos imprevistos como acidentes ou doenças enfrentadas pelos alunos ou seus familiares.A mudança na motivação por causa de situações imprevistas é relatada também em pesquisas como de Maia e Lima (2000) e de Moore e Kearsley (2007), os quais se referem a esse fator como barreiras situacionais que são acontecimentos que ocorrem em determinado momento da vida do indivíduo, como problemas de saúde, familiares e outros.

Segundo Cislaghi (2008, p. 258), a permanência do aluno é a "situação na qual o estudante mantém o interesse, a motivação e encontra na Instituição de Ensino Superior as condições que considera essenciais para permanecer frequentando regularmente o curso de graduação no qual ingressou", ou seja, o aluno se mantém matriculado até o termino do curso e sua certificação.

$\mathrm{Na}$ opinião dos participantes da pesquisa, o fator que mais contribui para sua permanência seria a motivação pessoal e a determinação. De acordo com Grossi e Nunes (2014), alunos menos motivados têm dificuldade em desenvolver habilidades necessárias aos estudos em cursos a distância, o que acarretaria o abandono. Para esses alunos, terminar o curso era algo que os impulsionaria a continuar, mesmo encontrando dificuldades.

Para Fiuza (2012), esse tipo de determinação está relacionado há dois tipos de motivação: a intrínseca e extrínseca A referida autora afirma que“a distinção mais básica é entre a motivação intrínseca, que se refere a fazer algo porque é inerentemente interessante ou agradável, e a motivação extrínseca, que se refere a fazer algo, pois leva a um resultado esperado". (Fiuza, 2012, pg. 51).Dessa forma, foi possível verificar nos relatos apresentados pelos questionários que a motivação estava mais relacionada às características extrínsecas, uma vez que os participantes alegaram a vontade em ter um curso superior na área da educação.

$\mathrm{Na}$ sequencia, outro fator que teria contribuído muito ou decisivamente para a permanência desse público seria a Flexibilidade de Horário para estudo. Como já fora dito anteriormente, os dados da presente pesquisa nos revelam que o "tempo" é um motivo de escolha em se fazer um curso na modalidade a distância, e a falta dele (do tempo), se mostrou como o principal motivo da evasão no curso analisado. 
Sendo assim, se uma das vantagens da EaD é poder escolher a hora e local para estudar, também pode ser uma desvantagem quando o aluno não consegue ter a exata dimensão do comprometimento necessário para o processo de estudos por meio de plataformas virtuais e por conseguinte não consegue estabelecer horários de estudo e organização para dedicação ao curso. De acordo com Paloff e Pratt(2002, pag. 76) "Ganha-se a flexibilidade do tempo, e também ganha-se a responsabilidade pela execução e participação nas atividades."

Outros dois motivos de permanência no curso apontados pelos alunos nos questionários estão diretamente ligados, à "Qualidade do Curso" e ao fato da instituição de Ensino ofertante ser uma "instituição conceituada". Para Grossi e Nunes (2014), esses fatores estão ligados a percepção que o estudante tem da instituição, como o prestígio da instituição e a qualidade do curso, decorrente da formação que recebe, e consequentemente, vincula esses fatores à utilidade do diploma.

\section{Causas da Evasão}

De acordo com os indicadores gerados no cotejamento entre os dados oficiais e as informações obtidas nas manifestações dos sujeitos da pesquisa por meio dos questionários, observou-se coerência entre os fatores apontados pelos alunos evadidos, com os fatores apontados pelos alunos em curso ou formados como os preditores para evasão.

Os questionários revelaram na categoria Desistência, 5 (cinco) subcategorias no Questionário 1, e 5 (cinco) subcategorias no Questionários 2. Entre essas 10 (dez) subcategorias foram evidenciadas na categoria Desistência, sendo que 3 (três) que se repetiram nos dois questionários, revelando assim o total de 7 (sete) subcategorias no total.

Dessa forma, essas 7 (sete) subcategorias reveladas pela análise de conteúdo, permitiram que as causas da evasão fossem divididas em dois grupos: causas endógenas e causas exógenas ao curso.

Causas exógenas ao curso são aquelas relacionadas aos fatores externos à instituição e ao curso em questão, como: falta de tempo para o estudo, demanda profissional e familiar, problemas de saúde na família e pessoal. 
As causas endógenas são aquelas diretamente relacionadas à instituição de ensino ofertante do curso, sendo:falta de comunicação da tutoria, problemas com material didático, interação e interatividade no ambiente virtual de aprendizagem (sentimento de solidão) e curso fora do perfil do aluno.

\section{Considerações Finais}

A evasão na $\mathrm{EaD}$ tem sido relatada como um problema que recorrente em todas as instituições de, independentemente dos níveis de ensino. Apesar da revisão da literatura realizada ter encontrado estudos sobre a evasão em cursos à distância, não foi verificada a existência de relatos de experiências ou programas de combate à evasão nessa modalidade. .

Por sua natureza qualitativa, esta pesquisa não buscou fazer generalizações. Partiu do pressuposto que ao apresentar questões a serem analisadas sobre o fenômeno da evasão na $\mathrm{EaD}$ e inferir algumas de suas causas, traria contribuições para o enfrentamento dos desafios da modalidade.

A partir da explanação a respeito das categorias identificadas e após a análise de conteúdo; as causas de evasão apontadas foram classificadas em endógenas ou exógenas ao curso. Foram classificadas como endógenas as causas ligadas ao curso, e portanto que podem ser evitadas pelas instituições de ensino, gerando a diminuição dos índices de evasão. Já as causas exógenas, relacionadas à vida e características pessoais dos estudantes, fogem do poder de manipulação das instituições, mas podem ser minimizadas quando identificadas e trabalhadas junto aos alunos matriculados.

Entre as causas exógenas ao curso, a falta de tempo para o estudo é de maior frequência entre os registros dos alunos. O fator tempo também é apresentado como um dos principais motivos da escolha da modalidade de ensino a distância pelos alunos. Faz-se necessário pontuar que, no Questionário 2, na categoria Persistência, ficou evidenciada a subcategoria Flexibilidade de Horário como um motivo para a persistência no curso.

Outro aspecto relevante quanto a noção de tempo foi a constatação de que ela variou de acordo com o grupo de alunos entrevistados. Se por um lado para os alunos evadidos havia a expectativa de pouco tempo para dedicação ao curso; por outro lado para os alunos que persistiram em seus estudos havia a expectativa de perceber o tempo 
como algo a seu favor, pois embora estudar a distância requeira dedicação assim como na educação presencial, esses alunos apresentaram o poder de organizar o espaço e o tempo para os estudos.

Sendo assim, o gerenciamento de estudo por parte do aluno se mostra recorrente nas pesquisas sobre evasão na $\mathrm{EaD}$ e se evidencia como um problema para essa modalidade. Muito frequentemente grande parte dos alunos se deparam com a falta de tempo ou com a inabilidade em organizar seus horários de estudo em um curso a distância. Esse indicador sinaliza para as instituições de educação a distancia o quão importante é dedicar períodos de formação aos profissionais que atendem esses estudantes - tutores, supervisores de área e coordenadores de polo, tendo em vista a importância de monitorar o acesso dos alunos desde o início do curso, auxiliando-os a compreender a ideia de tempo expressa nesse formato de ensino.

As respostas apontadas durante a pesquisa nos possibilitaram inferir que, caso seja detectado logo no início do curso o problema relativo à ideia de tempo e seja feita, prontamente, a orientação dos alunos com essa dificuldade, orientando-os quanto à necessidade de organização do tempo,o abandono do curso poderá ser evitado.

Ainda em relação às questões de organização do tempo e do acompanhamento dos alunos pela Instituição, é válido pontuar que essa pesquisa identificou que a maioria dos alunos evadidos alegaram ter abandonado o curso entre os Módulos II e III. Isso indica que ao iniciar as disciplinas curriculares, cabe à instituição perceber o que acontece no Módulo II parte de seus alunos a iniciarem o processo de evasão, fazendose necessário um monitoramento efetivo por parte da instituição.

Diante das considerações sobre a necessidade de acompanhamento efetivo dos alunos ao longo do curso, mostra-se imprescindível o monitoramento por parte da instituição, seja na forma de interação, de orientação ede feedbaks aos alunos. Na UABUFSCar, os tutores presenciais e virtuais são corresponsáveis pela formação de seus alunos e de acordo com os documentos oficiais desta instituição, na descrição de suas funções, os tutores têm um papel significativo no processo educacional, uma vez que a eles é destinada a reponsabilidade de acompanhar o processo de formação dos alunos, solucionando dúvidas, avaliando, motivando e mediando interações.

A pesquisa aqui apresentada revelou que existem problemas de interação entre tutores e alunos, tanto virtuais quanto presenciais, problemas inclusive apontados como uma das causas de evasão dos alunos. Em relação à tutoria, as dificuldades apresentadas pelos alunos indicam a necessidade de revisões e acompanhamento no trabalho desses 
profissionais para o desenvolvimento da $\mathrm{EaD}$ na instituição, uma vez que os tutores são os principais responsáveis pelo acompanhamento do processo formativo dos alunos, em especial no Ambiente Virtual de Aprendizagem (AVA).

Esse acompanhamento, destinado aos alunos no decorrer do curso, estaria relacionado também à formação de uma comunidade virtual de aprendizagem, formada por todos agentes envolvidos; o que evitaria o sentimento de solidão relacionado pelos alunos ouvidos como um fator fortemente relacionado ao abandono. Conclui-se, portanto, que quando os alunos não se sentem como parte do curso, ou da instituição e quando não conseguem interagir com seus colegas e professores, estão mais propensos a abandonarem seus estudos.

De acordo com as informações obtidas junto aos documentos oficiais da instituição pesquisada, percebe-seque a interação e a comunicação são características encontradas na proposta da UAB-UFSCar. Mas, o sentimento de solidão apontado pelos alunos sugere que desafios vêm sendo encontrados na construção de espaços de aprendizagem colaborativa próprios a modelos de educação a distância mais participativos. Portanto, mesmo que a instituição tenha tido a preocupação em oferecer no início do curso um Módulo Introdutório, fornecendo aos alunos uma formação voltada à familiarização com o ambiente virtual de aprendizagem e suas ferramentas, de fato a verdadeira cultura de aprendizagem colaborativa ainda não se formou.

Em relação às situações apontadas a respeito da participação dos tutores e da interação entre os agentes do processo educativo indicaram a necessidade de se repensar a formação desses profissionais e introduzir novas estratégias para promover a formação de uma comunidade virtual de aprendizagem no AVA, visto que esse ambiente é o principal espaço formativo virtual da UAB-UFSCar.

Outro aspecto relevante está relacionado à necessidade da criação de vínculo entrealuno e a instituição, e por conseguinte o combate ao sentimento de solidão; o que pode vir a ser uma das possibilidades de estabelecer o sentimento de pertencimento aos espaços de aprendizagem do Polo de Apoio Presencial.

De acordo com as orientações do modelo de EaD da UAB-UFSCar, os Polos de apoio presencial são constituídos com o objetivo de promover apoio ao processo de formação dos alunos e possibilitara interação e a comunicaçãodos estudantes entre si e com os agentes formadores. O Polo de apoio presencial deve ser um referencial da instituição para os alunos, oportunizando a formação de uma identidade das turmas e 
permitindo a socialização e a interação entre os alunos, aspectos necessários ao processo de aprendizagem.

Outro aspecto observado nesta pesquisa diz respeito a parte dos relatos dos alunos entrevistados, que indicaram que os Polos são frequentados apenas para a realização das atividades presenciais obrigatórias e em situações de apresentação de relatório de estágios. Portanto, pode-se compreender as formas de utilização efetiva do Polo de Apoio, seja por meio da promoção de aulas presenciais e de grupos de estudos, ou pelas oportunidades de vivências de outras atividades formativas podem vir a contribuir para a diminuição dos índices de evasão do curso.

O material didático, disponibilizado aos alunos, também necessita ser repensado. De acordo com os relatos apresentados pelos participantes da pesquisa, os alunos demonstraram que têm consciência de que se trata de um material de qualidade; porém, alegam que ele é de difícil compreensão "quando se tem que estudar sozinho".

Ao analisar os documentos disponibilizados pela UAB-UFSCar, foi possível perceber a preocupação e o cuidado da Instituição na produção do material didático para o curso, disponibilizado em diversas formas: mídias virtuais e eletrônicas, além do material impresso. Entretanto, estudos já apresentados mostram que, o material didático para $\mathrm{EaD}$ devem ter características próprias, como: dialogicidade, clareza, objetividade e deve ser desenvolvido por demanda, ou seja, de acordo com as características da clientela atendida.

Associados à carência de apoio por parte dos tutores e à falta de interação no AVA, as características do material didático se mostram como um conjunto de fatores que inviabilizam o modelo de $\mathrm{EaD}$, enquanto uma modalidade de ensino que se propõe a ampliar o acesso, a permanência e a formação de uma população que necessita estudar. Dessa forma, se faz necessário que a Instituição pesquisada avalie e pesquise junto aos seus alunos, a eficácia do material disponibilizado aos alunos, se este tem os auxiliado no processo de aprendizagem no curso.

Em relação ao perfil sociodemográfico dos alunos, a pesquisa aqui descrita revelou que as turmas analisadas eram compostas, majoritariamente, por pessoas do gênero feminino, com filhos e que já tinham uma atividade profissional. Nesse sentido, foi possível concluir que esse perfil funcionou como um fator que impulsionou a evasão do curso estudado, uma vez que os alunos afirmaram, em seus relatos, que imaginavam que o curso lhes daria condições de conciliar todas as atividades pessoais, profissionais juntamente às atividades de estudo. 
A UFSCar possui uma tradição de compromisso com a formação de professores e preza pela excelência na oferta de seus cursos, primando pela qualidade do ensino oferecido e promovendo a pesquisa acadêmica no Brasil, buscando garantir a mesma qualidade tanto em seus cursos presenciais quanto em seus cursos oferecidos na modalidade a distância. Entretanto, quando se trata de $\mathrm{EaD}$, é imprescindível que as especificidades dessa modalidade sejam levadas em consideração e que questões sobre $\mathrm{o}$ atendimento ao perfil dos alunos seja problematizado e constantemente avaliado.

Nesse sentido, é preciso que os dados sóciodemográficos sejam avaliados e que o perfil da turma ingressante seja considerado, no momento do planejamento dos cursos. Os documentos disponíveis sobre a instituição afirmam que há dois questionários que devem ser respondidos pelos alunos ingressantes, um no momento da inscrição no vestibular e outro na ocasião da matrícula, o que possibilita à Instituição ter um conjunto rico de dados sociodemográficos desses estudantes. É possível concluir que a Instituição incluir nesses questionários perguntas que levantem, também, as características motivacionais, cognitivas, profissionais, além de hábitos e estratégias de aprendizagem dos alunos. Isso contribuiria sobremaneira para a caracterização de um perfil comportamental que pudesse dar indicadores para atualização do desenho do curso.

A partir da análise dos questionários aplicados, verificou-se que parte dos alunos participantes desta pesquisa se manifestaram favoráveis à oferta de apenas uma disciplina por vez, para que a quantidade de atividades pudesse ser condizente com a realidade de vida dos entrevistados. Não se trata de colocar em risco a qualidade do curso, mas, que ele tivesse uma característica de adaptabilidade ao perfil de seus alunos.

Por fim, é possível acreditar que as discussões construídas com base nos dados recolhidos e analisados durante essa pesquisa possam contribuir na compreensão do fenômeno da evasão na EaD e possam subsidiar as instituições ofertantes desses cursos no combate ao abandono discente. Essas contribuições, porém, estariam longe de colocar um ponto final nas discussões referentes à evasão nos cursos da modalidade a distância, por ser este um assunto complexo. Mas o intuito da pesquisa aqui descrita foi fomentar novas reflexões e estudos e, dessa forma, contribuir para a diminuição dos percentuais de evasão dos cursos.

Entende-se que a Educação a Distância tem um grande potencial em atender à demanda de educação superior no Brasil, podendo atender à necessidade emergente da formação de professores para Educação Básica. Entretanto, essa oferta de cursos 
de formação de professores na modalidade a distância deve estar inserida em uma política educacional de formação de professores,sempre amparada em parâmetros de qualidade, visando contribuir com a melhoria da educação no país.

Nesse sentido, a UAB representa uma política educacional de grande abrangência, no que tange à expansão da $\mathrm{EaD}$ no Brasil. E é a partir dessa perspectiva que acredita-se ser imprescindível que se reflita acerca do Sistema UAB no cenário da EaD brasileira, contemplando uma análise da gestão e da política de democratização do ensino superior. Assim, entende-se que pesquisas com os egressos do Sistema podem servir para a verificação da efetividade e eficácia da política de educação a distância, que têm como propósito primeiro a democratização e a universalização do Ensino Superior no país

\section{Referências}

ABBAD, G. \& Borges-Andrade, J.E. (2004). Aprendizagem Humana em Organizações e Trabalho. In: Zanelli, Borges-Andrade, Bastos (Orgs) Psicologia: Organizações e Trabalho no Brasil, 237-275. Artmed: Porto Alegre, RS.

ALMEIDA, O. C. S. de. Evasão em Cursos a Distância: validação de instrumento, fatores influenciadores e cronologia da desistência. 2007. 177 f. Dissertação (Mestrado em Administração) - Universidade de Brasília, Brasília - DF 2007.

BARDIN, L. Análise de conteúdo. São Paulo: Editora 70. 2008.

BRASIL. Decreto 5.800. Dispõe sobre o Sistema Universidade Aberto do Brasil. Diário Oficial da União, 08 de junho de 2006.

BELLONI, M.L. Mídia educação e educação a distância na formação de professores. In: MILL, D.; PIMENTEL, N.M., Educação a distância: desafios contemporâneos. 2010. Cap. 16, p.245-266.

Censo EAD.BR - Relatório Analítico da Aprendizagem a Distância no Brasil 2012", realizado pela Associação Brasileira de Educação a Distância (ABED).

CISLAGHI, Renato. Um Modelo de Sistemas de Gestão do Conhecimento em um Framework para a Promoção da Permanência Discente no Ensino de Graduação. Tese, UFSC, Florianópolis, 2008.

FIUZA, P. J. Adesão e permanência discente na Educação a Distância: Investigação de motivos e análise de preditoressociondemográficos, motivacionais e de personalidade para o desempenho na modalidade. Tese (Doutorado em Psicologia) - Universidade Federal do Rio Grande do Sul, 2012. 
GROSSI,M G R; NUNES, RC. Comparação entre as características e percepções de alunos em curso e dos evadidos de um curso técnico a distância do IF Fluminense. Revista EDaPECI São Cristóvão (SE) v.14. n. 3, p. 470-494 set./dez. 2014. Disponível em www.seer.ufs.br/index.php/edapeci/article/download/2346/pdf. Acesso em $15 / 10 / 2015$.

LITWIN, E. Educação a Distância: temas para o debate de uma nova agenda educativa. Porto Alegre: Artmed Editora, 2001.

LÜDKE, Menga, ANDRÉ, Marli. Pesquisa em Educação: abordagens qualitativas. São Paulo: EPU, 1986.

MAIA, M. de C.; MEIRELLES, F. de S. \& PELA, S. K. (2009). Análise dos índices de evasão nos cursos superiores a distância no Brasil. In:CONGRESSO INTERNACIONAL DE EDUCAÇÃO A DISTÂNCIA, 10. Salvador: Associação Brasileira de Educação a Distância (ABED), 2004. Disponível em: <http://www.abed.org.br/congresso2004/por/pdf/073-TC-C2.pdf >. Acesso em 13/02/2013.

MAIA, M., C. MEIRELES, F.S. Evasão nos Cursos a Distância e sua relação com as Tecnologias da Informação e Comunicação. In: ENCONTRO DA ANPAD, 29, 2005, Brasília, DF. Anais... Brasilia, DF: ANPAD, 2005. 1CD-Rom.

MOORE, M. e KEARSLEY. Educação a Distância: uma visão integrada. São Paulo: Cengage Learning, 2008.

MOURA-WALTER, A. Variáveis Preditoras de Evasão em Cursos a Distância. Dissertações de Mestrado, Instituto de Psicologia da Universidade de Brasília, Brasília. 2006.

OBBADI, M. \& JURBERG, C. (2005). Educação a distância: algumas reflexões sobre a desistência. Tecnologia Educacional. Ano 33, n. 167/169.

OLIVEIRA, M. M. Como fazer pesquisa qualitativa. Petrópolis, Vozes, 2007.

PACHECO, M. M. Políticas de Educação Profissional: A Evasão no Curso Técnico em Secretariado do Programa E-Tec Brasil no Paraná. 2011. 139 f. Dissertação (Mestrado em Educação) - Universidade Tuiuti do Paraná, Curitiba, 2011.

PALLOF. R. M., \& Pratt, K. (2004). O aluno virtual: um guia para trabalhar com alunos online. Porto Alegre: Artmed.

PRETI, O. (Org.) Educação a Distância: sobre discursos e práticas. Brasília: Líber Livros, 2005,

REZER, E. Educação a Distância: Expansão Nacional, Presença no Estado de Mato Grosso E Formação e Professores. V Colóquio Internacional de Políticas e Práticas Curriculares, UFMT, 2009. 
ROSSETTI, G.; ALVES, M.L.N. O Tutor em Foco: Diferenças entre O Virtual E O Presencial. UFSCar, 2007.

SANTOS, E.M. dos et al. (2008). Evasão na educação a distância: identificando causas e propondo estratégias de prevenção. Disponível em: <http://www.abed.org.br/congresso2008/tc/511200845607PM.pdf $>$ Acesso em 2/02/2013.

SOUZA, C. A.; SPANHOL, L. F. J.; LIMAS, J. C. O.; CASSOL, M. P. Tutoria na Educação a Distância, 2004. Disponível em http://abed.org.br/congresso2004/por/htm/088-TC-C2.htm. Acesso em 25/10/2015.

UMEKAWA \& ZERBINI. Evasão e persistência em ações educacionais a distância: análise do perfil discente. Rev. Psicologia. Organ. Trab., abr-jun 2015, vol. 15 num 2, pp. 188-200.

VARGAS, M.R.M; LIMA, S.M.V. Barreiras a implantação de Programas de Educação e Treinamento à Distância. Salvador, 2004. Disponível em: http://www.abed.org.br/congresso2004/por/htm/092-TC-C3.htm. Acesso em $18 / 02 / 2013$.

VILARINHO, L. R. Goulart \& PARO, E. F. Ensino Superior E Educação A Distância: Uma Proposta Para Diminuir A Evasão De Alunos. 2008. Disponível em www.abed.org.br/congresso2008/tc/511200845607PM.pdf. Acesso em 13/02/2013.

\section{Como referenciar este artigo}

LAHAM, Stelamary Aparecida Despincieri.; LEMES, Sebastião de Souza. Um Estudo sobre as possíveis causas de evasão em curso de Licenciatura em Pedagogia a distância. Revista on line de Política e Gestão Educacional, Araraquara/SP, v. 20, n. 3, p. 405431, 2016. Disponível em: <http://dx.doi.org/10.22633/rpge.v20.n3.9753>. ISS: 15199029.

Submetido em: junho/2016

Aprovado em: agosto/2016 